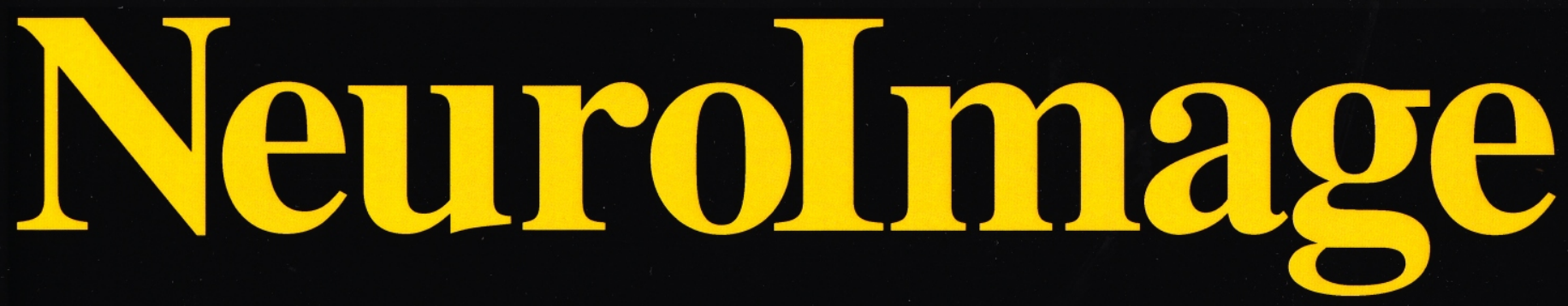

Editor-in-Chief

\title{
Peter Bandettini
}

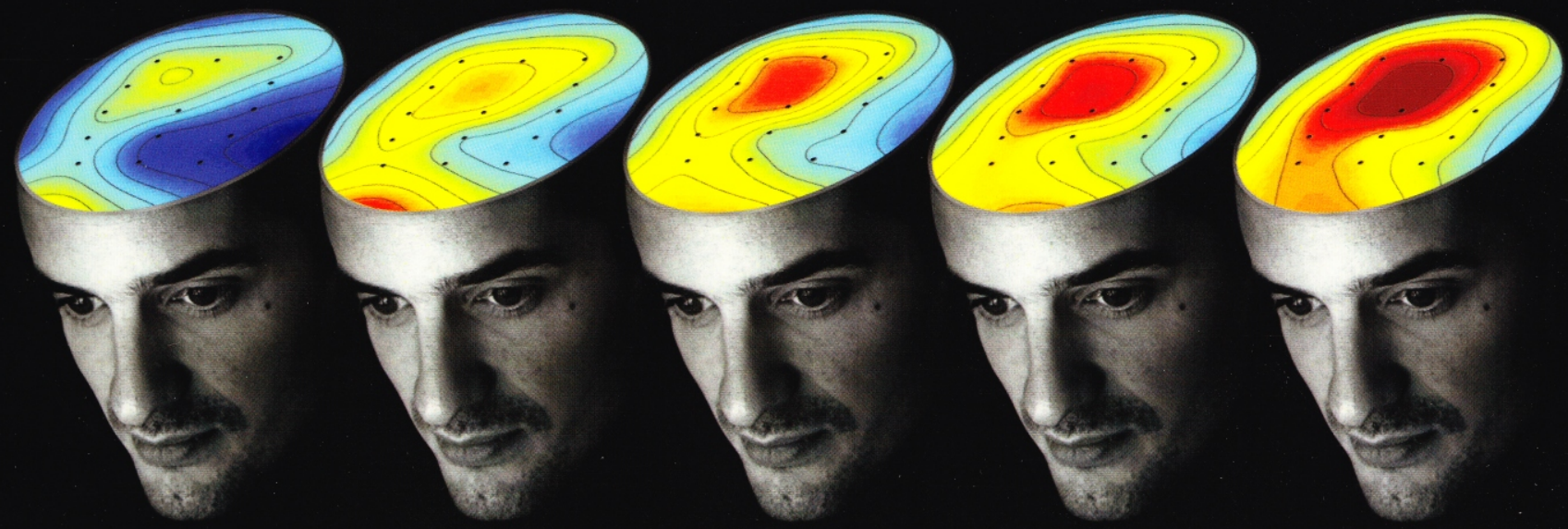

Table

Table
Table
Table

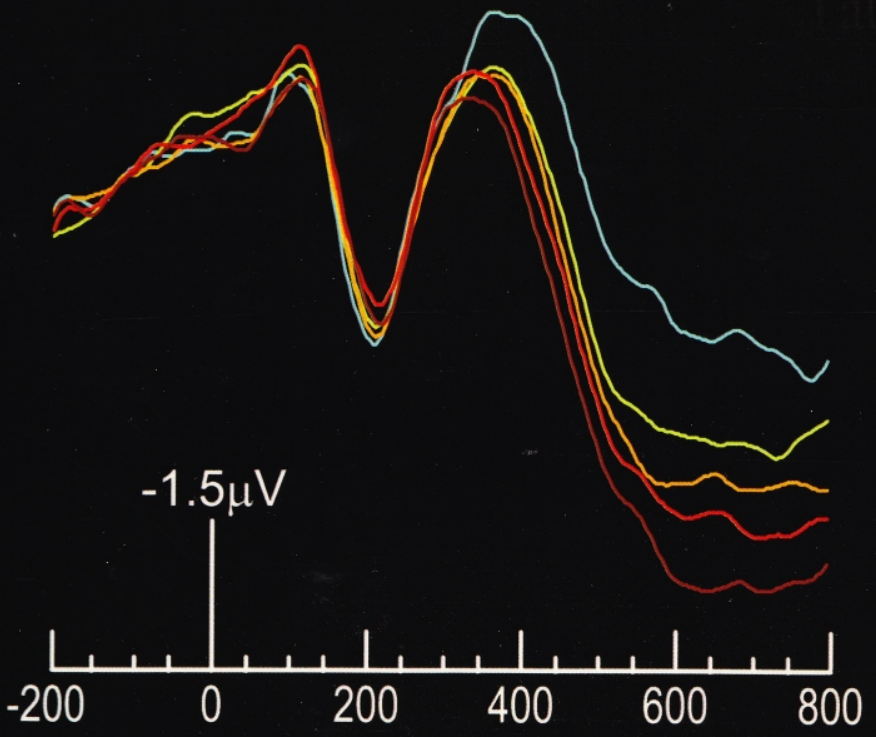

Table

Table

Table

Table

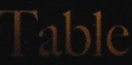




\title{
From N400 to N300: Variations in the timing of semantic processing with repetition
}

\author{
Louis Renoult ${ }^{\mathrm{a}}$, Xiaoxiao Wang ${ }^{\mathrm{b}}$, Vincent Calcagno ${ }^{\mathrm{c}}$, Marie Prévost ${ }^{\mathrm{d}}$, J. Bruno Debruille ${ }^{\mathrm{d}, *}$ \\ a Rotman Research Institute, Baycrest, Toronto, Ontario, Canada \\ ${ }^{\mathrm{b}}$ Department of Anatomy and Cell Biology, McGill University, Montréal, Québec, Canada \\ c INRA, Sophia-Agrobiotech Institute, Sophia-Antipolis, France \\ d Department of Psychiatry, McGill University, Montréal, Québec, Canada
}

\section{A R T I C L E I N F O}

Article history:

Accepted 22 February 2012

Available online 3 March 2012

\section{Keywords:}

Semantic memory

Repetition

Event-related potentials

N400

LPC

\begin{abstract}
A B S T R A C T
The present study aimed to explore the variations of semantic processing according to the number of target words (i.e., 4, 12 and 24) and according to the number of repetitions (i.e, 1 to 15). The number of targets had no impact on the $\mathrm{N} 400$ brain potential, the index of semantic processing, nor on the late positive component (LPC), an index of episodic encoding and retrieval. Analyses of the effects of the number of repetitions showed that the duration of semantic processes - assessed by measuring N400 latency - was linearly shortened along repetitions while their extent - as indexed by N400 amplitude - remained constant after the second presentation. In contrast, the extent of episodic processes - as indexed by LPC amplitude - was found to increase linearly with repetition. By showing that N400 latency may be much less stable than previously thought, these results bring new constraints on the functional correlates of this key stage in the processing of semantic information. They also suggest that semantic processes can be studied at high repetition rates whatever the number of target stimuli. Finally, our findings show that each episode of prior presentation has an impact on the late processing of a stimulus despite the absence of an explicit memory task.
\end{abstract}

(c) 2012 Elsevier Inc. All rights reserved.

\section{Introduction}

Thirty years of research have shown that the N400 event-related potential (ERP) constitutes a default response of the brain to the processing of semantic information (for a review, see Kutas et al., 2006). The N400 is a negative deflection which develops between 200 and $500 \mathrm{~ms}$ after stimulus onset and has a broad scalp distribution, with maximum amplitudes at centro-parietal electrode sites (Curran et al., 1993). Its neural generators have been found to correspond to the extended semantic memory network described by functional neuroimaging studies (reviewed in Binder et al., 2009; Martin, 2001), including the anterior medial temporal lobe, the posterior temporal cortex, the temporoparietal junction and the ventrolateral prefrontal cortex (Elger et al., 1997; Guillem et al., 1995, 1999; Halgren et al., 1994; Smith et al., 1986). The N400 has been recorded in response to various stimuli, including visual and auditory words, drawings, photographs, faces or environmental sounds (Kutas et al., 2006). Its amplitude has been shown to be modulated by any type of semantic relations between the stimulus and preceding items, namely category (fruit-apple; e.g., Heinze et al., 1998), functional (broom-sweep; Bach et al., 2009), synonymy (street-road ; Liu et al., 2003), antonymy (black-white; Kutas and Iragui, 1998),

\footnotetext{
* Corresponding author.

E-mail address: bruno.debruille@mcgill.ca (J.B. Debruille).
}

schema (restaurant-wine; Chwilla and Kolk, 2005), or world knowledge ("The taxis in New York City are yellow"; Hagoort et al., 2004) and also by associative relations (mouse-cheese; Franklin et al., 2007). In contrast, the latency of this component, which typically peaks around $400 \mathrm{~ms}$ after stimulus onset, is considered to be relatively stable (Federmeier and Laszlo, 2009; Voss and Federmeier, 2011) and has rarely been used as a dependent measure. This contrasts with behavioral studies for which manipulation of the same semantic variables results in response time differences. The stability of N400 latency was recently hypothesized to be crucial for the binding of different semantic features into a coherent whole, a process that N400 activity would reflect (Federmeier and Laszlo, 2009; see also Kutas and Federmeier, 2000).

Only a few studies have reported variations in N400 latency. The most common finding consisted of delayed peak latency. We will briefly review these studies, considering only those that have used visually presented words since auditory presentation can result in anticipations or delays, depending on the duration of the stimulus or on the possibility of its identification before acoustic offset (Karniski et al., 1993; Pratarelli, 1995; Van Petten et al., 1999). In a study in which sentences were presented at the rapid rate of 10 words per second (Kutas, 1987), N400 peak latency evoked by the final words of these sentences was found to be delayed by about 80 to $100 \mathrm{~ms}$ compared to when sentences were presented at slower rates ( 1 or 2 words per second). In an influential study, Holcomb (1993) investigated the impact of the visual degradation of words on the N400 
effect of semantic priming. In the critical condition, target words were degraded by removing a random $33 \%$ of each letter or by overlaying a matrix of dots. The peak latency of the N400 effect was delayed by approximately $40 \mathrm{~ms}$ when target words were degraded compared to when they were not. Similarly, in a semantic priming task with masked primes, Kiefer (2002) found an 80 ms delay in N400 peak latency (N480) compared to a condition when primes were not masked. Finally, D'Arcy et al. (2005) designed a study in which participants had to study one or two sentences and hold them in working memory to later perform a congruity judgment on a third sentence. They found a 50 ms delay in N400 peak latency (N450) with increasing memory load. This delay was correlated with individual working memory capacity.

Taken together, these results suggest that, in the visual modality, the semantic processing indexed by $\mathrm{N} 400$ can be delayed or prolonged with increased perceptual difficulty or memory load. However, more recent results suggest that $400 \mathrm{~ms}$ is not indicative of a minimal duration for the semantic processing reflected in N400 activity to occur and that this ERP component can also peak earlier. Using highly repeated words in semantic categorization tasks, Debruille and Renoult (2009) and Renoult and Debruille (2011) reported that the N400 could peak as early as 300 to $330 \mathrm{~ms}$ after word onset (see also Simon et al., 2004 for similar findings in a lexical decision task). These early N400s were shown to be sensitive to the same variables as the N400s obtained in non-repeated conditions. Namely, they were modulated by semantic priming (across SOAs), semantic category and concreteness and were not affected by physical matching (Debruille and Renoult, 2009; Renoult and Debruille, 2011; Renoult et al., 2010, 2012). Despite the observation that these N400s peaked much earlier for highly repeated words than non-repeated words, it could be demonstrated that the onset of the deflections themselves was the same in both conditions (around $230 \mathrm{~ms}$ after word onset; Debruille and Renoult, 2009). This is concordant with numerous observations showing that the onset latency of the N400 does not vary much in the visual modality, starting 200 to $250 \mathrm{~ms}$ after word onset in various conditions (Deacon et al., 1995; Hagoort et al., 2004; Helenius et al., 1998; van Berkum et al., 1999). Behavioral studies also show that there may be a minimal latency after which reaction times (RTs) can no longer be decreased. When no repetition is included, mean RTs in semantic categorization tasks are typically around 900-950 ms depending on the specific conditions and the population (reviewed in Chang, 1986). In the semantic categorization task of Renoult and Debruille (2011), trials were divided into five levels of repetitions $(0-20,20-40,40-60,60-80$, and 80-100) and a progressive reduction in RTs was found until a floor of about $800 \mathrm{~ms}$ post-target onset was reached. Note that this floor is certainly task specific, since in non-semantic tasks, such as recognition memory, mean RTs to repeated words can be as short as $600 \mathrm{~ms}$ post-target onset (Van Strien et al., 2005). However, the chronological information that RTs offer does not only reflect the process of interest, such as semantic processing, but also evaluative and decision processes. Using the N400 as a measure of the duration of semantic processing, and not just as an index showing that this processing has taken place, is thus of special interest.

N400 effects evoked by highly repeated words are thus characterized by a shorter duration (i.e., peak latency) but not an earlier onset (Debruille and Renoult, 2009). It might be concluded from these studies that the use of high rates of repetition results in a shortening of the duration of semantic processing. Thus, while the onset of these processes would be quite stable, their duration could vary with stimulus novelty. This time variation could be as important as the variations of the amplitude of the N400 for identifying the nature of N400 computations, which, almost certainly, constitute a key stage in the processing of semantic information (Kutas et al., 2006). However, the relation between $\mathrm{N} 400$ latency and repetition is still ambiguous for 2 reasons. First, these studies did not include analyses of individual levels of repetition. In Debruille and Renoult (2009), 30 presentations of the same words were compared to non-repeated conditions. This study thus does not clarify if N400 latency is stable across different repetition levels, or if massive repetition is necessary to shorten the duration of semantic processing. The same reserves can be applied to Renoult and Debruille (2011). Even though, in this study, trials were divided into five levels of repetitions (0-20, 20-40, 40-60, 60-80, and 80-100), this still constitutes a high level of repetition and no latency analyses were conducted. Second, only two target words were used in these experiments. One possibility is that this small number could have influenced the duration of semantic processing, possibly via a mechanism similar to that described by D'Arcy et al. (2005). Accordingly, the two target words could be active in working memory all along the experiment and available for fast semantic comparison with the primes. Modulations of N400 with working memory load have now been observed in several studies (D'Arcy et al., 2005; Gunter et al., 1995; Salisbury, 2004) but only D'Arcy et al. (2005) have reported latency variations. In any case, one has to note that experiments in which brief N400 activity has been described were not working memory tasks and thus that the number of target words might not have been crucial to participants. A second possibility therefore is that it would be the high rate of repetition itself and not the number of target words which would be responsible for shorter semantic processing. If one considers short-term memory as the sets of elements from long-term memory that are currently in an activated state (Cowan, 1988, 1993; Ranganath and Blumenfeld, 2005), the semantic representations of all recently presented target words could be activated throughout the experiment. Results from repetition priming experiments in which multiple items stay active in memory for a long time are illustrative of this type of processes (Cowan, 1988). This conception of short-term memory thus does not involve a strict limited capacity as is the case for working memory (Awh et al., 2007; Luck and Vogel, 1997). According to this view, the use of massive repetition would have resulted in increased activation of the semantic representations of target words and would have allowed faster comparison with the primes. This increase in activation could be proportional to the number of repetitions, until a maximal level is reached. This is compatible with the progressive reduction and plateau observed in RTs in our previous study (Renoult and Debruille, 2011).

The goal of the present study was to investigate the factors that promote an abbreviated semantic processing in repeated conditions. We tested the 2 following hypotheses. First, the duration of semantic processing, as indexed by N400 latency, varies with the number of target words used. When this number is lower than working memory capacity, early N400 latency will be observed. Second, N400 latency is inversely proportional to the number of presentations of the relevant stimuli. Its latency will decrease linearly with repetition until a plateau is reached. To test these hypotheses, we used 3 semantic categorization tasks, which differed only in the number of target words used $(4,12$ and 24). Each word was repeated 15 times. In the condition where 4 target words were used, working memory could theoretically be used to process these words faster. In contrast, with 12 and especially with 24 words, working memory should be overloaded, even if these words are repeated. To be sure that this would be the case, we used a pseudo-random mode of presentation which resulted in increasing average lags between each word presentation with increasing number of target words (see methods section). The first hypothesis would thus predict that N400 peak latency would increase from 4 to 12 target words and possibly from 12 to 24 target words. Crucially, the use of 24 words in conjunction with a high number of participants (28) allowed us to study individual levels of repetition ( 1 to 15 ). If the second hypothesis is correct, this study should reveal a decrease in $\mathrm{N} 400$ peak latency proportional to the number of presentations. Rather than comparing specific levels of repetition, we performed trend analyses to investigate whether a polynomial 
function, linear or quadratic (falling and then rising or vice versa) would best fit the effects of repetition. In addition to the amplitude and latency of the N400, we measured those of the late positive component (LPC). This ERP is often associated with episodic recollection (Friedman and Johnson, 2000; Mecklinger, 2000; Paller and Kutas, 1992; Rugg and Curran, 2007). In continuous recognition paradigms in which multiple presentations were included, it was shown that LPC amplitude could provide a graded reflection of the number of stimulus repetitions (Segalowitz et al., 1997; Van Strien et al., 2005). In contrast, no latency modulations were reported in these studies. The LPC thus constitutes an interesting comparison to the $\mathrm{N} 400$ for the processing of words that are repeated multiple times. Because these studies used explicit memory tasks (i.e., recognition) and a relatively small number of repetitions (respectively 3 and 9), we were interested to see if the graded increase in LPC amplitude could be observed at a higher repetition rate (i.e., 15) and in a task in which stimulus repetition had no explicit experimental relevance.

\section{Methods}

\section{Participants}

30 subjects ( 15 women) participated in 3 semantic categorization tasks. Participants were right-handed French native speakers who reported being free of neurological and psychiatric disorders. They were recruited by newspaper advertisements among people aged between 18 and 40 years who had at least a college level of education (mean age: $26 \pm 5$ ). Two subjects were excluded from the analyses due to excessive blinking and multiple behavioral responses to the same items, respectively. All participants signed an informed consent form accepted by the Douglas Institute Research and Ethics Board.

\section{Tasks and procedure}

Participants were seated comfortably in a dimly lit room in front of a computer screen placed $1 \mathrm{~m}$ from their eyes. In all 3 semantic categorization tasks, black words, written in Boston 15 font, were presented at the center of the screen in lower-case on a white background. This screen was a HP Ultra VGA 1024 used at its maximum resolution (i.e., $1024 \times 768$ ). The Boston 15 font letters had an average length of $0.3 \mathrm{~cm}$ and a height of $0.4 \mathrm{~cm}$. Prime words were presented for $500 \mathrm{~ms}$ and target words for $1000 \mathrm{~ms}$. Stimulus onset asynchrony (SOA) between primes and targets was $1000 \mathrm{~ms}$. 1 to $1.5 \mathrm{~s}$ after the offset of the target stimulus, a blink instruction 'clignez des yeux' appeared for $1000 \mathrm{~ms}$. The next trial began after a time interval that randomly varied between $800 \mathrm{~ms}$ and $1500 \mathrm{~ms}$.

The order of the 3 semantic categorization tasks was randomized across subjects. Each task differed only in the number of target words used: 4,12 or 24 . For each task, participants were instructed to press one of two keys with their right index finger as rapidly and as accurately as possible according to whether the target word was from the same semantic category as the prime or not. In half of the trials, the target word semantically matched the prime word. In the other half, it did not. Each target word was repeated 15 times. The mean lag between repetitions of the same target word was $4 \pm$ 2.8 in the 4 target condition, $12 \pm 7.2$ in the 12 target condition and $23 \pm 24.1$ in the 24 target condition. The primes were the category words 'animal' (same spelling and meaning as in English) and 'objet' (i.e., 'object' in English), presented in lower-case. There were a total of 40 different target words $(4+12+24)$, half were names of animals and half were names of objects. The mean number of letters of target words was $7( \pm 1.4)$ and the mean base-10 logarithm of their frequency of usage was $2.98( \pm 0.7)$, according to the Brulex database (Content et al., 1990). Names of animals and objects did not differ in average number of letters and frequency. To ensure that each word was used as frequently in each of the 3 semantic categorization tasks, 10 lists containing different combinations of the target words were created. Each list included words for each of the semantic categorization tasks and was used in 3 participants.

\section{Data acquisition}

The accuracy and reaction times (RTs) of participants were recorded for each trial. The EEG was recorded with tin electrodes mounted in an elastic cap (Electrocap International) from 30 points, all referenced to the right ear lobe. Twenty-eight of these points were placed according to the extended International 10-20 System (Electrode nomenclature committee, 1991). These electrode sites could be grouped in a sagittal subset, which comprised $\mathrm{Fz}, \mathrm{FCz}, \mathrm{Cz}$, and Pz; a para-sagittal subset, including FP1/2, F3/4, FC3/4, C3/4, $\mathrm{CP} 3 / 4, \mathrm{P} 3 / 4$, and $01 / 2$; and a lateral subset, including $\mathrm{F} 7 / 8, \mathrm{FT} 7 / 8$, $\mathrm{T} 3 / 4, \mathrm{TP} 7 / 8$, and $\mathrm{T} 5 / 6$. The remaining two electrodes were placed below each eye in order to allow the monitoring of vertical eye movements by comparing their EEG signals to those derived from FP1 and FP2. The monitoring of horizontal eye movements was done by comparing F8 to F7 signals. The impedance was kept below $5 \mathrm{k} \Omega$. The EEG was amplified 20,000 times by Contact Precision amplifiers. High and low-pass filter half-amplitude cut-offs were set at .01 and $100 \mathrm{~Hz}$, respectively, with an additional $60 \mathrm{~Hz}$ electronic notch filter. Signals were then digitized on-line at a sampling rate of $256 \mathrm{~Hz}$ and stored along with stimulus and response codes for subsequent averaging using the Instep (version 4.3) software package.

EEG epochs contaminated by eye movements, excessive myogram, amplifier saturations or analog to digital clippings were removed offline by setting automatic rejection criteria. Trials for which analog to digital clipping exceeded a $100 \mathrm{~ms}$ duration, and electrodes for which amplitude exceeded $\pm 100 \mu \mathrm{V}$ were excluded from averaging. We then further ensured that that this procedure was effective and that the signals recorded by frontal electrodes were not contaminated by ocular activity in the resulting averaged files. For vertical eye movements, this was done by comparing the activity recorded by FP1/2 channels to that recorded by the electrodes placed below each eye, subject by subject and condition by condition, looking for polarity inversions. Similarly, for horizontal eye movements, we compared F8 signal to F7 signal and looked for polarity inversions that could signal ocular activity. No subject had to be reaveraged after this inspection.

\section{Data processing and measures}

Mean reaction times (RTs) for each condition were computed using only the correct responses and excluding the trials in which participants took more than $2000 \mathrm{~ms}$ to respond. ERPs to target words were computed by averaging the $1000 \mathrm{~ms}$ EEG epochs of these trials in each experimental condition, using a -200 to $0 \mathrm{~ms}$ baseline before target onset.

To measure the amplitude of the N400, we computed the mean voltage respective to the baseline in a time window that was chosen with a mid-peak latency technique, also referred to as the fractional latency approach in the guidelines of Picton et al. (2000). This was done because the N400-like potential observed with high rates of repetition was shown to peak earlier than the classic N400 (Debruille and Renoult, 2009; Renoult and Debruille, 2011; Renoult et al., 2010). All the following measures were taken at $\mathrm{Cz}$ electrode. The latency of the negative peak that appeared between 200 and $500 \mathrm{~ms}$ on the grand average of unprimed trials was first measured. In the three tasks, this negative peak culminated around $350 \mathrm{~ms}$ after target word onset. We then measured the peak latencies of the preceding P200s, which peaked around $210 \mathrm{~ms}$ in the 3 tasks. These latencies were added to those of the $\mathrm{N} 400$ and the sum was divided by 2 . The result was used as the onsets of the N400 time windows. Similarly, the peak latencies of the N400 were added to those of the succeeding LPCs and 
the result was divided by 2 to obtain the offsets of the N400 time windows. Since the LPC peak latency slightly differed in the 3 tasks, the average of the 3 peaks was taken. The window of measure obtained for the N400 was $280-480$ ms. The LPC was measured in a consecutive window of the same width (as in Renoult and Debruille, 2011), that is, 480 to $680 \mathrm{~ms}$ after word onset.

The peak latencies of the N400 and LPC were measured in each subject and at each electrode by assessing the timing of the maximum of the negative and positive peaks, respectively, observed in their respective time windows. It was verified in individual participants and across levels of repetitions (in the 24 target condition) that these time windows appropriately capture the variations of latencies in both ERP components. To correct for high-frequency noise, we applied the peak \% routine of Instep 4.3 using a 10\% correction. This procedure, which is similar to waveform smoothing, results in the averaging of data points within $10 \%$ of the amplitude of the maximum peak in the selected time windows.

\section{Statistical analyses}

For analyzing behavioral data, we ran two series of repeatedmeasures ANOVAs. One was made for the numbers of errors (accuracy) and the other for mean RTs (excluding incorrect responses). They had both semantic priming (primed vs. unprimed trials) and number of target words $(4,12$ or 24$)$ as within-subject factors.

For ERP data, 3 repeated-measures ANOVAs were performed with the same within-subject factors as the RT analysis plus the electrode factor: one for the sagittal subset, one for the para-sagittal subset and one for the lateral subset of electrodes. For the para-sagittal and the lateral subsets, another within-subject factor, hemiscalp (right vs. left), was included. The Greenhouse and Geisser (1959) procedure was used to compensate for possible violations of the sphericity assumption associated with the electrode factor, which had more than two levels. In this case, the original degrees of freedom are reported together with the epsilon $(E)$ and the corrected probability level.

In the semantic categorization task with 24 targets, a sufficient number of trials ( 24 targets words $\times 28$ subjects) ${ }^{1}$ was available for an analysis of ERP effects across levels of repetition, by grouping primed and unprimed words. In this task, another ANOVA was thus performed with the number of presentations (16 levels) as withinsubject factor, and without semantic priming. In addition to testing the significance of this factor, we performed trend analyses to investigate whether a polynomial function, linear or quadratic, would best fit the effect of repetition. This analysis allowed us to get an idea of the distribution of the effect of repetition on the ERP amplitudes and latencies (instead of comparing specific levels of repetition, the outcome of which would primarily reflect statistical power). To limit the number of statistical tests performed, we restricted these analyses to the sagittal subset of electrodes where the two ERP components had their maximal amplitudes.

\section{Results}

\section{Behavioral data}

\section{Comparison between the three tasks}

The analyses of errors showed that subjects were accurate in their responses, with a mean error rate of $1 \%$ that did not significantly differ between the 3 tasks ( $1.45 \%$ for 4 targets, $1.35 \%$ for 12 targets, and $1.15 \%$ for 24 targets).

The ANOVA on mean reaction times (RTs) revealed that there was no main effect of target number $(p>.4)$, showing that mean RTs were

\footnotetext{
${ }^{1}$ For instance, this is approximately equivalent to having 45 trials by condition and 15 participants or 55 trials by condition and 12 participants, and is thus considered a sufficient number of trials for most N400 effects (Duncan et al., 2009).
}

similar in the 3 conditions ( $850 \mathrm{~ms}$ for 4 targets, $840 \mathrm{~ms}$ for 12 targets and 849 ms for 24 targets; see Fig. 1A). The effect of semantic priming was significant $\left(F_{1,27}=22.68, p<.001\right)$ but it did not interact with target number $(p>.5)$. Mean difference between unprimed and primed trials was thus equivalent for the 3 conditions ( $60 \mathrm{~ms}$ for 4 targets, $64 \mathrm{~ms}$ for 12 targets and $60 \mathrm{~ms}$ for 24 targets).

\section{Effects of the number of presentations in the 24 target condition}

This analysis revealed a main effect of the number of presentations $\left(F_{15,405}=10.91, p<.001\right)$ with significant linear $\left(F_{1,27}=\right.$ $13.98, p=.001)$ and quadratic components $\left(F_{1,27}=26.98 p<.001\right)$. Since the main difference in RTs was between the first and second presentation $\left(F_{1,27}=22.99, p<.001\right.$; see Fig. $1 \mathrm{~B}$ and $\left.\mathrm{C}\right)$, another analysis was conducted in which the first presentation was excluded. This analysis showed that the effect of the level of repetition was
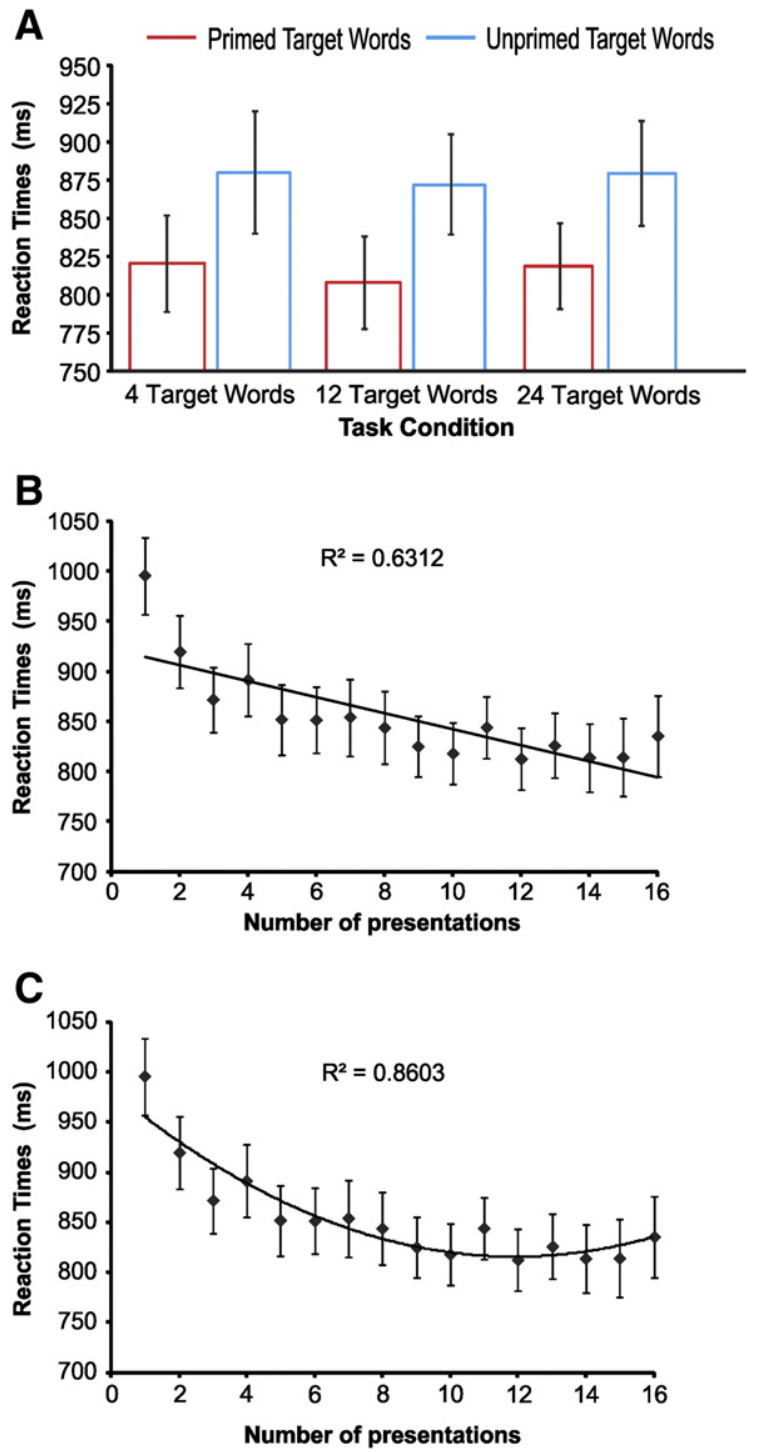

Fig. 1. (A). Mean reaction times (RTs) in the 3 task conditions: 4,12 and 24 target words. Mean RTs are in red for primed and in blue for unprimed trials. Standard error bars are shown for each condition. (B). Mean RTs according to the number of presentations ( 1 to 16 ) in the 24 target condition. Standard error bars are shown for each presentation. Primed and unprimed trials were averaged together. The distribution of all presentations is fit with a linear trend line with associated R-squared value. (C). Same as B, except that the graph is fit with a quadratic trend curve. (For interpretation of the references to color in this figure legend, the reader is referred to the web version of this article.) 
still highly significant $\left(F_{14,378}=5.19, p=.001\right)$, as well as its linear $\left(F_{1,27}=7.72, p=.01\right)$ and quadratic components $\left(F_{1,27}=11.03\right.$, $p=.003)$, the latter being the best fit for the distribution of the effect of the number of presentations on RTs. RTs indeed decreased rapidly for the first repetitions but then much more slowly and moderately for the last repetitions.

\section{A}

\section{Target Words}

\section{— Primed Target Words $\quad$ Unprimed Target Words}
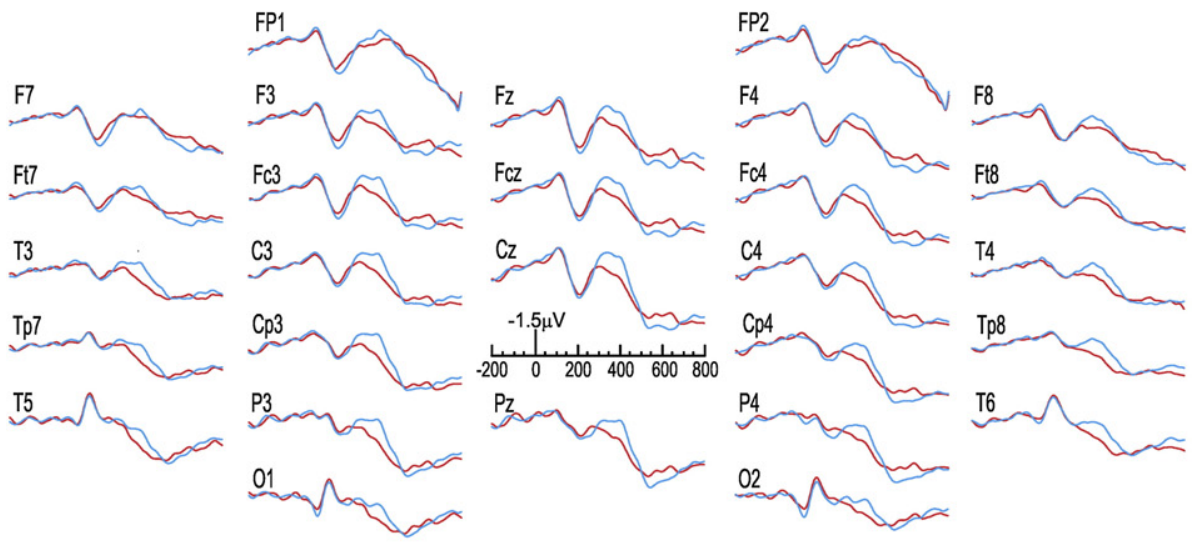

B

12 Target Words

— Primed Target Words $\quad$ Unprimed Target Words

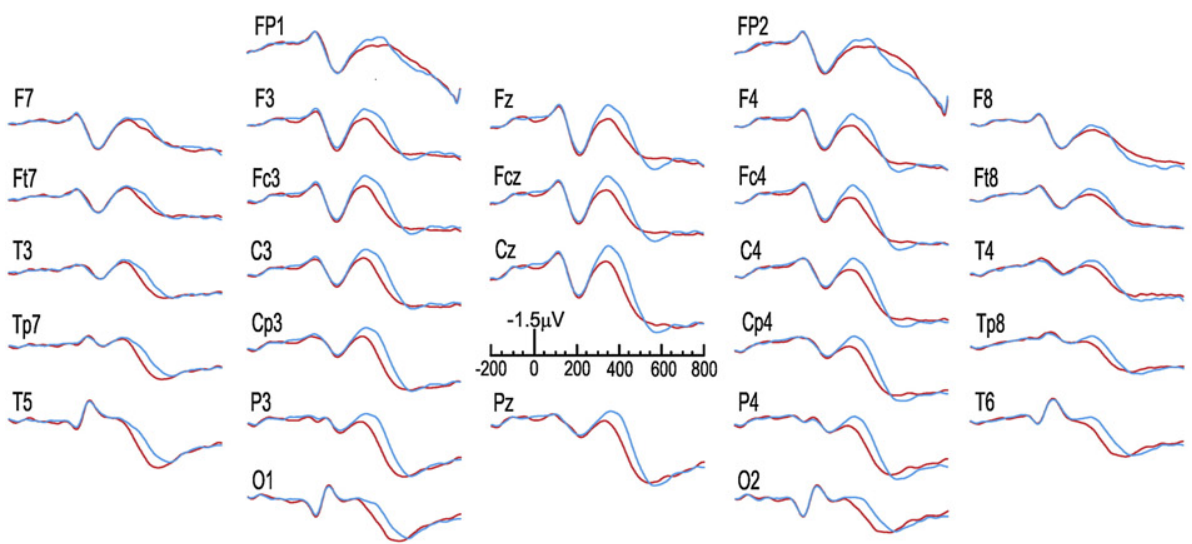

C 24 Target Words

— Primed Target Words — Unprimed Target Words

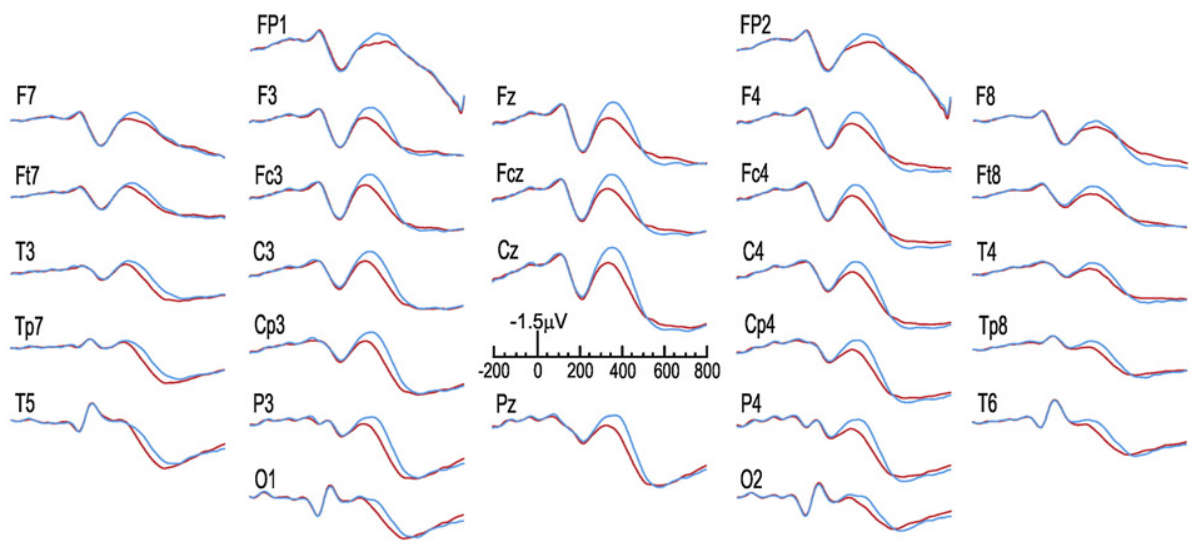

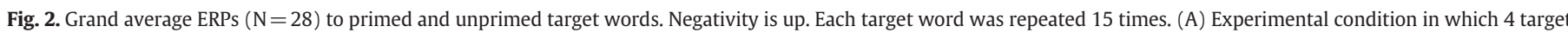
words were used. (B) 12 target words. (C) 24 target words. 


\section{Electrophysiological data}

\section{Comparison between the three tasks}

N400 Amplitude. The ANOVAs on the mean voltage amplitudes of the N400 revealed no main effect of target number for any subset of electrodes (all $p>.2$ ). The effect of priming was significant for each subset $\left(F_{1,27}=15.63, p=.001\right.$ for the sagittal, $F_{1,27}=13.93, p=.001$ for the para-sagittal and $F_{1,27}=19.12, p<.001$ for the lateral subset of electrodes; see Fig. 2). This effect appeared slightly greater at left than right parietal sites in the 4 target condition, whereas it was more symmetrical in the 12 and 24 target conditions (see Fig. 3). However, there was no significant interaction between priming and the number of target words or between these factors and the electrodes and hemiscalp factors (all $p>.2$ ).

N400 peak latency. The ANOVAs on the peak latencies of the N400 revealed no main effect of target number for any subset of electrodes, nor any interaction with priming (all $p>.2$ ). There was a main effect of semantic priming for all subsets of electrodes $\left(F_{1,27}=11.69\right.$, $p=.002$ for the sagittal, $F_{1,27}=17.05, p<.001$ for the para-sagittal and $F_{1,27}=19.79, p<.001$ for the lateral subset of electrodes), showing that N400 peaked significantly earlier for primed than unprimed trials (see Fig. 2). For the sagittal and para-sagittal subsets, there were significant interaction between priming and the electrodes factors $\left(F_{3,81}=4.69, \varepsilon=.801, p=.009\right.$ for the sagittal and $F_{6,162}=5.83$, $\varepsilon=.601, p<.001$ for the para-sagittal subset). Follow-up analyses showed that the $\mathrm{N} 400$ peaked significantly earlier for primed than unprimed trials at $\mathrm{Fz}, \mathrm{Cz}, \mathrm{Pz}, \mathrm{P} 4 / \mathrm{P} 3, \mathrm{~F} 4 / \mathrm{F} 3, \mathrm{FC} 4 / \mathrm{FC} 3, \mathrm{C} 4 / \mathrm{C} 3, \mathrm{CP} 4 / \mathrm{CP} 3$ and $02 / 01(F \geq 7, p \leq .01$; mean difference: $21 \mathrm{~ms} \pm 4)$.

LPC amplitude. The ANOVAs on the mean voltage amplitudes of the LPC revealed no main effect of target number for any subset of electrodes, nor any main effect of priming (all $p>.1$ ). There was a significant interaction between priming and the hemiscalp factor at the para-sagittal subset $\left(F_{1,27}=10.74, p=.003\right)$, showing that, for this subset, there was a greater difference between primed and unprimed trials over the right than the left hemiscalp (see Fig. 2). However, further analyses showed that the effect of priming was not significant for either hemiscalp (all $p>.1$ ).

LPC peak latency. The ANOVAs on the peak latencies of the LPC revealed no main effect of target number for any subset of electrodes, nor any interaction with priming (all $p>.3$ ). There was no main effect of priming but interactions between priming and the electrodes factors at the sagittal and lateral subsets $\left(F_{3,81}=3.19, \varepsilon=.69, p=.047\right.$ for the sagittal and $F_{4,108}=3.48, \varepsilon=.61, p=.029$ for the lateral subset). Follow-up analyses showed that the LPC peaked significantly earlier for primed than unprimed trials at T6/T5 (mean difference: $15 \mathrm{~ms} ; F_{1,27}=9.16, p=.005$ ) and TP8/TP7 (mean difference: $10 \mathrm{~ms}$; $\left.F_{1,27}=5.05, p=.033\right)$.
Effects of the number of presentations in the 24 target condition

N400 amplitude. The ANOVAs on the mean voltage amplitudes of the N400 revealed no main effect of the number of presentations, but an interaction between this factor and electrodes $\left(F_{45,1215}=2.49\right.$, $\varepsilon=.169, p=.015)$ with significant linear $\left(F_{1,27}=10.83, p=.003\right)$ and quadratic components $\left(F_{1,27}=9.96, p=.004\right)$. Further analyses showed a significant effect of the number of presentations at $\mathrm{Pz}$ $\left(F_{1,27}=9.82, p=.005\right.$, with a significant linear component: $F_{1,27}=$ $8.23, p=.009)$ and a similar trend at $\mathrm{Cz}\left(F_{1,27}=1.79, p=.078\right)$. However, as visible on Figs. 5A and B for electrode $\mathrm{Cz}$, this effect was likely influenced by the strong repetition effect occurring between the first and second presentations, which was significant at these electrode sites $\left(F_{1,27}=6.38, p=.019\right.$ at $\mathrm{Cz}$ and $F_{1,27}=5.75, p=.025$ at $\left.\mathrm{Pz}\right)$. This was confirmed by another analysis which showed that the effect of the number of presentations disappeared at $\mathrm{Cz}$ and $\mathrm{Pz}$ when the first presentation was excluded (all $p>.1$ ).

N400 peak latency. The ANOVAs on the peak latencies of the N400 revealed a main effect of the number of presentations $\left(F_{15,405}=3.31\right.$, $p=.001)$ with a significant linear component $\left(F_{1,27}=23.09\right.$, $p<.001)$. Once again, since the main difference in latencies was between the first and second presentation $\left(F_{1,27}=6.75, p=.016\right.$; see Figs. $5 \mathrm{C}$ and $\mathrm{D}$ ), another analysis was conducted in which the first presentation was excluded. This analysis showed that the effect of the level of repetition was still highly significant $\left(F_{14,378}=2.88\right.$, $p=.003)$, as well as its linear distribution $\left(F_{1,27}=15.68, p<.001\right)$. As seen on Fig. 5C and D for Cz electrode (see also Fig. 4), the latency of N400 decreased progressively with repetition but the quadratic distribution (Fig. 5D) only slightly differed from the linear distribution (Fig. 5C) and thus did not significantly improve the fit $(p>.8)$.

LPC amplitude. The ANOVAs on the mean voltage amplitudes of the LPC revealed a main effect of the number of presentations $\left(F_{15,405}=3.69\right.$, $p=.001)$ with a significant linear component $\left(F_{1,27}=8.27, p=.008\right)$ and a trend for a quadratic distribution $\left(F_{1,27}=3.31, p=.08\right)$, perhaps due to the greater difference between the first and second presentation $\left(F_{1,27}=7.46, p=.011\right.$; see Figs. $6 \mathrm{~A}$ and $\left.\mathrm{B}\right)$. This was confirmed by another analysis in which the first presentation was excluded, which showed a main effect of the number of presentations $\left(F_{14,378}=1.99, p=.04\right)$ with a linear trend $\left(F_{1,27}=4.1, p=.045\right)$ but no significant quadratic distribution $(p>.7)$. As shown in Fig. 6A (linear fit at $\mathrm{Cz}$ ) and 6B (quadratic fit), the amplitude of LPC increased progressively with repetition.

LPC peak latency. The ANOVAs on the peak latencies of the LPC revealed no main effect of the number of presentations, nor any interaction with the electrodes factor $(p>.2)$. The level of repetition nonetheless showed a significant quadratic distribution $\left(F_{1,27}=5.41\right.$, $p=.028$ ), likely due to an observable decrease and then increase in the peak latency of the LPC between the first and the last repetitions
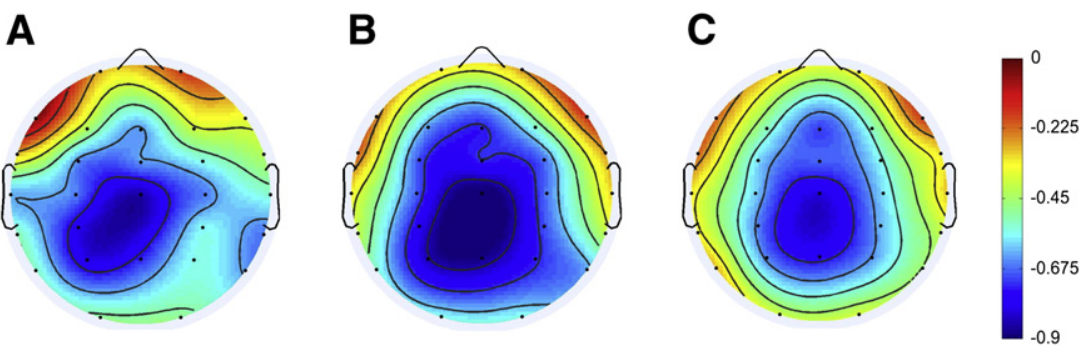

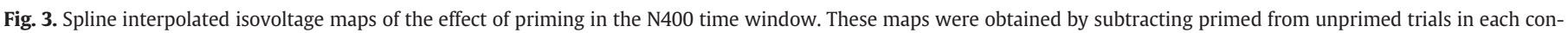
dition (A) 4 target condition. (B) 12 target condition. (C) 24 target condition. 


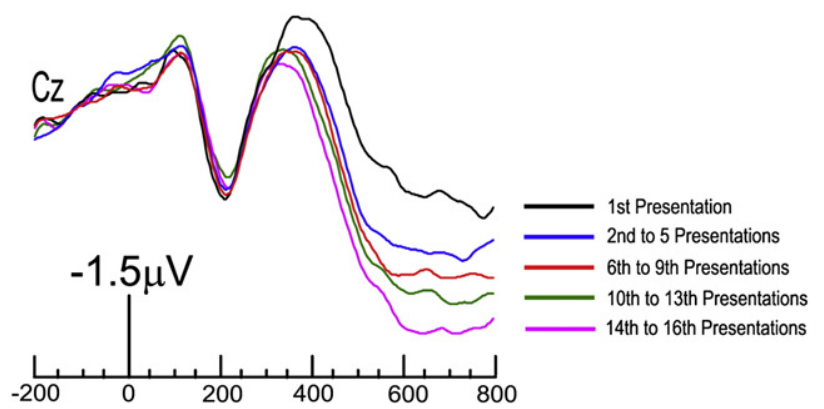

Fig. 4. Grand average ERPs $(\mathrm{N}=28)$ at various levels of repetition in the 24 target condition. Primed and unprimed trials were averaged together.

(see Fig. 6D for a quadratic fit at $\mathrm{Cz}$ electrode). However, another analysis excluding the first presentation showed that this effect was not as robust as that observed for the N400 latency, the quadratic distribution being just a trend in this case $\left(F_{1,27}=3.98, p=.06\right)$.

Correlations with reaction times. To explore possible relations between the ERP and behavioral measures, we computed correlations between the mean RTs and N400 peak latencies and between the mean RTs and LPC amplitudes. These variables were chosen because they were associated with significant effects of the number of presentations (either linearly or quadratically). Spearman's rank correlations $\left(r_{s}\right)$ were computed in each participant across presentation levels (1 to 16). 11 correlations between N400 latencies and RTs were individually significant $(p<0.05)$. Despite great variability among individuals, most correlations (23 out of 28 ) were positive, with an average of 0.27 (using Fisher's Z transform). Combining all of them revealed a significant overall correlation (Fisher's combined probability test: $\mathrm{X} 2=135.5$; $p<0.01$ ). Thus $\mathrm{N} 400$ consistently peaked earlier when RTs were shorter.

17 correlations between LPC amplitudes and RTs were individually significant $(p<0.05)$, with an average of -0.42 (using Fisher's Z transform). Combining all of them revealed a significant overall correlation
(Fisher's combined probability test; X2 $=232.27 ; p<0.01$ ). LPC amplitudes were thus greater when RTs were shorter.

\section{Discussion}

The goal of the present study was to identify the factor(s) that promote an abbreviated semantic processing in semantic categorization tasks using massively repeated words (Debruille and Renoult, 2009; Renoult and Debruille, 2011). N400 event-related potentials (ERPs) in these studies were characterized by onset latencies similar to those observed in non-repeated conditions but much earlier peaks (around 300 to $330 \mathrm{~ms}$ after word onset). These previous experiments used high rates of repetition but also a very limited number of target words (i.e., 2). We therefore tested the following hypotheses: 1 - The duration of semantic processing, as indexed by N400 latency, varies with the number of target words used. 2 N400 latency is inversely proportional to the number of presentations of the relevant stimuli. It decreases linearly with repetition until a minimal latency is reached. In contrast with the first hypothesis, results showed that effects of semantic priming on ERPs and reaction times (RTs) were similar for 4, 12 and 24 target words. In accordance with the second hypothesis, the peak latency of the N400 linearly decreased with the number of presentations. These findings suggest that repetition itself rather than the number of target words used can shorten the duration of semantic processing.

Behavioral and ERP results showed that the effects of semantic priming were significant but did not vary with the number of target words used. Error rates and mean RTs were similar with 4, 12 or 24 words, suggesting that the number of targets did not influence task difficulty. This is compatible with the finding that, in non-repeated conditions, category size (i.e, birds vs. animals) does not influence categorization time (Collins and Quillian, 1970). Moreover, N400 latency but also its amplitude and scalp distribution did not differ significantly with the number of target words. These results are thus incompatible with the hypothesis that the duration of semantic processing, as indexed by N400 latency, varies with the number of target words used. This could have been mediated by an activation of these
A

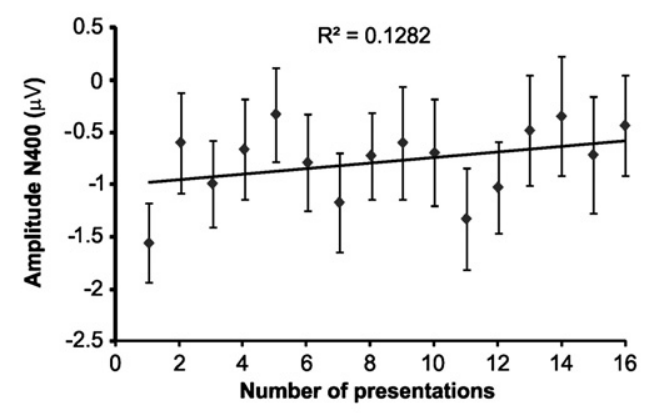

C

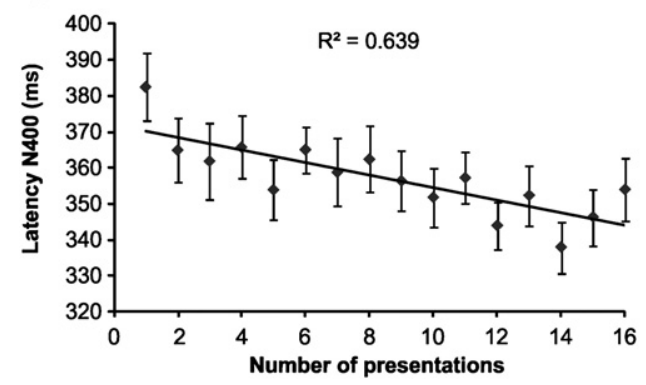

B

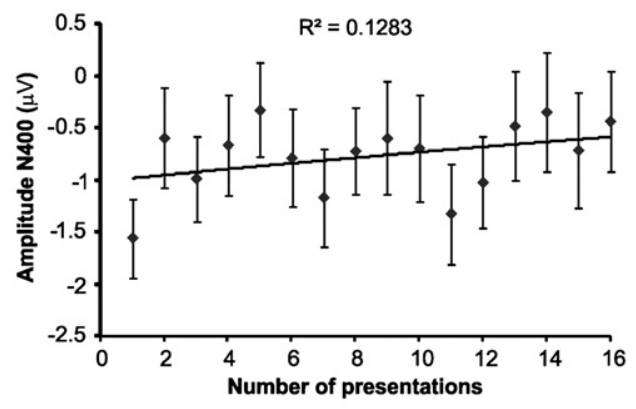

D

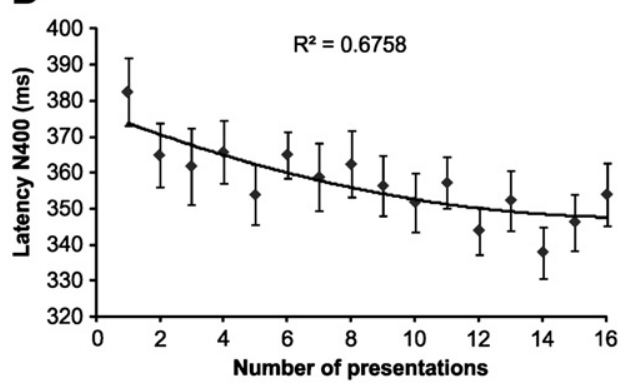

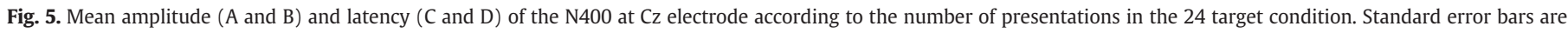

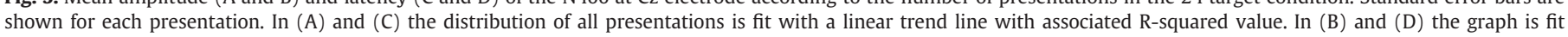
with a quadratic trend curve. Primed and unprimed trials were averaged together. 

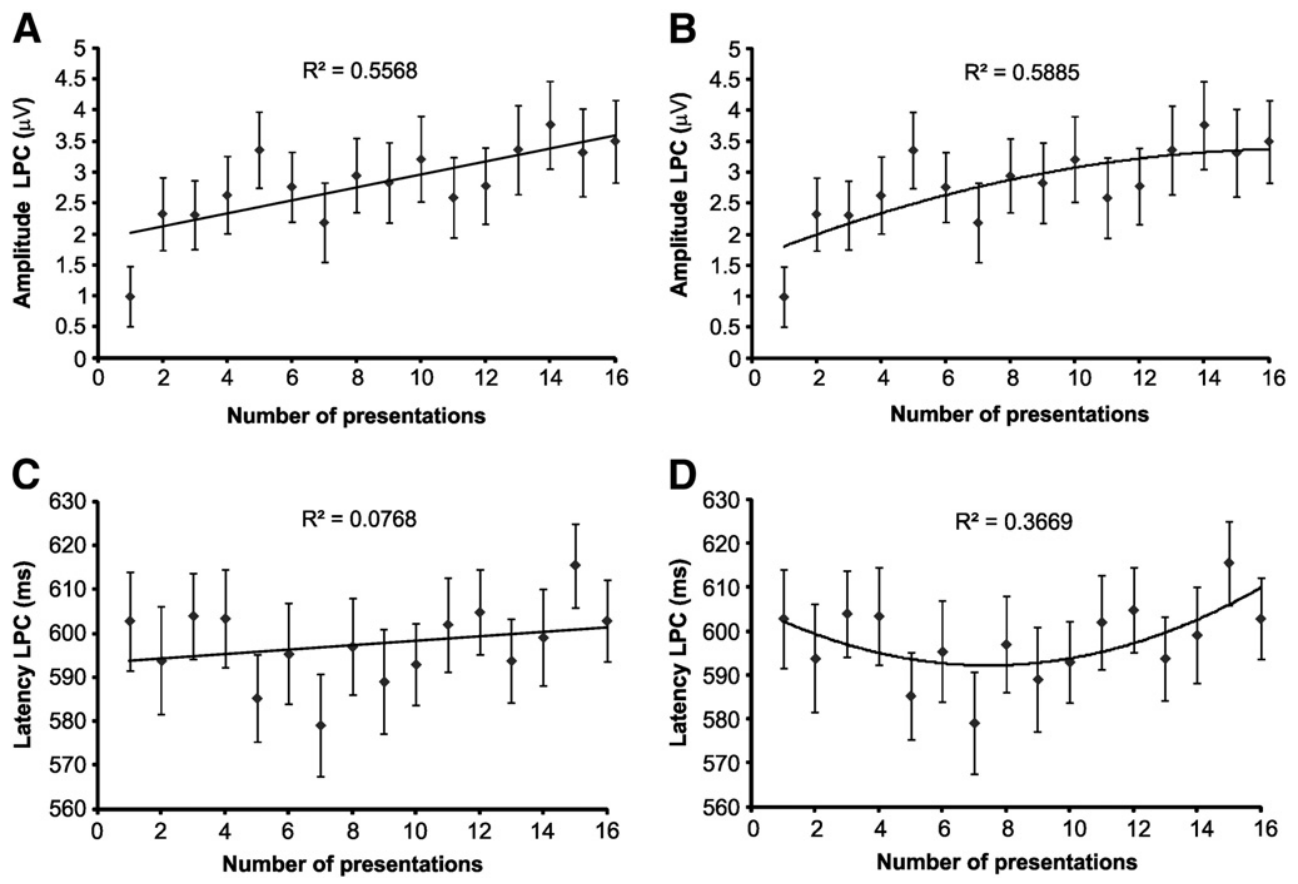

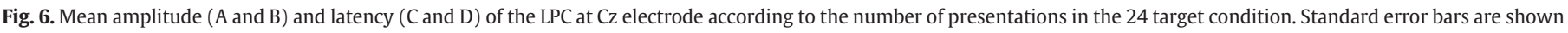

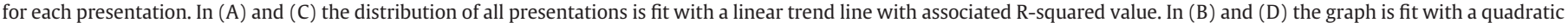
trend curve. Primed and unprimed trials were averaged together.

words in working memory throughout the experiments, since their number in our previous studies and in the 4 target condition was clearly inferior to working memory maximal capacity and that N400 latency has been shown to vary with working memory load (D'Arcy et al., 2005). The fact that it was not the case and that N400 latency did not differ between 4,12 and 24 targets indicate that the exact number of target words is not crucial for studies investigating semantic processing with high rates of repetition.

The present results revealed for the first time a linear decrease of N400 peak latency with repetition, thus confirming the second hypothesis. Analyses of the effect of the number of presentations in the 24 target condition showed that from about $380 \mathrm{~ms}$ after word onset at the first presentation, which is similar to the estimation of Voss and Federmeier (2011) as the typical N400 latency in young adults (i.e., $375 \mathrm{~ms}$ ), N400 peaked around $340 \mathrm{~ms}$ at the end of the experiment. These findings therefore suggest that the presence of early N400 latencies in previous studies was due to the use of multiple repetitions (Debruille and Renoult, 2009; Renoult and Debruille, 2011). As we have proposed in the introduction, it is compatible with the view that considers short-term memory as the sets of elements from long-term memory that are currently in an activated state (Cowan, 1988, 1993; Ranganath and Blumenfeld, 2005). This view is typically illustrated by results from repetition priming experiments in which multiple items stay active in memory for a long time (Cowan, 1988). Accordingly, the use of massive repetition would have resulted in a progressive increase in activation of the semantic representations of all target words, which would reach faster the level at which they can be compared with the primes. This abbreviated semantic processing was seen both in RTs and in the latency of the N400. RTs showed a quadratic modulation with repetition: they decreased rapidly for the first presentations and much more slowly afterwards (the global decrease was from 995 to $812 \mathrm{~ms}$ after word onset). There was a small positive correlation between RTs and N400 latencies, with N400 peaking earlier when RTs were shorter. In contrast, we found a strong negative correlation between LPC amplitudes and RTs. The amplitude of this component thus tended to be greater when RTs were shorter. Even though the effect of repetition on the amplitude of the LPC was best fit by a linear distribution, the quadratic distribution only slightly missed significance $(p=0.08)$. This quadratic trend could explain why the amplitude of the LPC showed a stronger relationship with RTs than N400 latency.

The shorter RTs observed in the present study (i.e., $812 \mathrm{~ms}$ after word onset) were very similar to those of Renoult and Debruille (2011; i.e., $811 \mathrm{~ms}$ ), which indicates that $800 \mathrm{~ms}$ may be an approximation of a minimal response time in semantic categorization tasks. As for the N400, it is likely that the latency that it attained here after more than 10 presentations (about $340 \mathrm{~ms}$ after word onset) also represents an approximation of a minimal latency. In Renoult and Debruille (2011), a peak latency of about $330 \mathrm{~ms}$ after target onset was observed with the use of 200 presentations and a similar design. However, this may also vary with experimental conditions. In Debruille and Renoult (2009), N400 was recorded to category words primed by exemplars (i.e., the opposite order of presentation as in here and in "classic" semantic categorization designs) and an even shorter latency (290 ms after target onset) was observed with 30 presentations. Behavioral studies have shown that different categorization levels were also associated with different reaction times (Collins and Loftus, 1975; Collins and Quillian, 1969; see also Chang, 1986). It is however unclear if it was the use of categories instead of exemplars or the unusual order of presentation that was responsible for these even earlier N400s. Moreover, the designs of our previous studies, especially the very low number of target words, did not allow us to conduct an analysis of individual levels of repetition. This was made possible in the present design by the use of a higher number of target words (i.e., 24), a high rate of repetition (15) and a large number of participants (28).

Analyses of the effects of the number of presentations showed, both for RTs and ERPs, that the greater repetition effect occurred between the first and the second presentation. In accord with a number of previous studies, N400 amplitude did not significantly vary with the number of presentations after this initial repetition effect (Besson et al., 1992; Kazmerski and Friedman, 1997; Kounios and Holcomb, 1992; Van Strien et al., 2005; Young and Rugg, 1992). In contrast, the amplitude of LPC increased linearly with repetition 
and thus gave a graded reflection of the number of presentations. Previous studies reporting similar effects had used explicit memory tasks (i.e., recognition memory) and lower rates of repetitions (Johnson et al., 1985; Segalowitz et al., 1997; Van Strien et al., 2005). The fact that similar modulations of LPC with repetition were observed in a semantic task and with unchanged context may indicate that the encoding of unique aspects of events (i.e., different presentations) may be an automatic process. In contrast to its amplitude, the latency of the LPC did not vary with the number of presentations (see Johnson et al., 1985 for similar findings interpreted as P300 activity). These modulations of LPC are interesting to contrast with those of the N400, especially the absence of modulation of N400 amplitude after the second presentation. One of the main functions of the semantic memory system is to categorize the world based on similarities (Barsalou, 2008; Komatsu, 1992; Murphy, 2002). Accordingly, semantic representations allow us to identify new objects as members of a category and infer unseen properties of these objects such as their functions or characteristics (Murphy, 2002). However, in accordance with this perspective, once an object has been categorized (i.e., tomato) and its properties extracted (i.e., edible), the conceptual system may no longer be oriented to this particular object. N400 amplitude, as an index of semantic processing, is thus especially sensitive to the novelty effect (i.e., first versus second presentation) but not much modulated by further presentations. In contrast, episodic memory is the form of declarative memory which allows us to recollect unique events (Tulving, 2002). If I were to remember a particular tomato among others, I would have to identify and encode something unique about it, such as contextual details. If an ERP component such as the LPC reflects episodic recollection (reviewed in Rugg and Curran, 2007), it would thus be expected that it allows discriminating the potential uniqueness of events at encoding. Linear modulations of LPC amplitude with multiple presentations would be compatible with such function. Accordingly, the distinct modulations of N400 and LPC amplitudes with repetition that we have described can be seen as illustrative of some of the main functions of the semantic and episodic memory systems. The semantic system is biased towards similarity whereas the episodic system is biased towards uniqueness. Interestingly, the results of a recent fMRI study suggest that the stability of semantic processing across repetitions could be a necessary condition for episodic encoding. In two semantic tasks and a face encoding task, Xue et al. (2010) showed that the similarity of neural activity across repetitions in many brain regions was the best predictor of subsequent memory (i.e., recognition and recall) for words or faces. Because of the different time resolutions of fMRI and EEG, the similarity of neural activity across repetitions observed in this study cannot be directly related to N400 activity. However, it will be particularly interesting to correlate N400 activity across repetition levels with subsequent memory in future studies.

The question arises as to why variations in N400 peak latency with repetition may have been unnoticed in previous studies. First, most studies including repetition in their design have used only two presentations. The linear variation in latency that we have reported needed multiple presentations to be observed. Second, this effect was relatively small. Accordingly, the strong repetition effect on N400 amplitude occurring at the second presentation could have obscured any difference in latency. For instance, in the present experiment, N400 was reduced by about $60 \%$ of its amplitude at the second presentation, whereas its latency was reduced by only $5 \%$. The effect of repetition on $\mathrm{N} 400$ latency is thus relatively small compared to its effect on N400 amplitude. This difference in magnitude and the use of low rates of repetition are likely to be the main causes why the relation between N400 latency and repetition was largely unknown. Moreover, as noted by Deacon et al. (1995), this is also the result of a generally held belief that N400 latency is stable (at least in comparison to the P300) and thus rarely measured. These authors reported earlier N400 peak latency for primed than for unprimed trials (about $20 \mathrm{~ms}$ earlier). This phenomenon was also observed in the present study. N400s to primed trials peaked about 20 ms earlier than for unprimed trials. This effect was observed at most electrode sites. The number of trials was insufficient to test if this effect would interact with the number of presentations. However, in Deacon et al. (1995) study, the difference of latency between primed and unprimed words was observed in unrepeated conditions and was very similar to the difference reported here. Moreover, our previous studies showed that the effect of semantic priming on N400 amplitude did not vary with different levels of repetition (Debruille and Renoult, 2009; Renoult and Debruille, 2011). If N400 latency was modulated differently for primed and unprimed trials with repetition, this would likely influence the magnitude of the effect of priming. Taken together, these observations suggest that small but significant differences in N400 latency between primed and unprimed trials may exist independently of repetition. Future studies will be necessary to directly test if this effect can be replicated in repeated as well as in non-repeated conditions.

\section{Conclusion}

The present results demonstrate that repetition itself rather than the number of target words used can shorten the duration of semantic processing, as indexed by N400 latency. The findings of variations in N400 latency with repetition as well as with priming illustrate that its latency may be less stable than previously thought. This opens a new avenue of research as the study of the variables that modulate the duration of N400 might reveal as much about the functional significance of this ERP as did the variables that modulate its amplitude. On the other hand, we have shown in previous studies that the amplitude of N400 recorded after multiple repetitions is sensitive to the same variables as in non-repeated conditions, namely semantic priming (across SOAs), semantic category and concreteness and that it is not modulated by physical matching (Debruille and Renoult, 2009; Renoult and Debruille, 2011; Renoult et al., 2010, 2012). The present study confirmed the maintenance of semantic priming effects with repetition and demonstrated that these effects can be studied with various numbers of target words. Moreover we have replicated, with a greater number of presentations and in a task in which stimulus repetition had no explicit experimental relevance, the finding of a linear increase in LPC amplitude with repetition. We have proposed that these distinct modulations of N400 and LPC amplitudes with repetition are illustrative of some of the main functions of the semantic and episodic systems: to categorize the world based on similarities vs. to extract the uniqueness of experiences. The new type of semantic paradigms that we are describing may be especially useful in specific populations in which the use of numerous non-repeated targets is inherently problematic, for instance in developmental studies or in the study of individual patients. Indeed, the possibility of repeating words means that, despite the limited number of good exemplars of a particular semantic category, one can have hundreds of target stimuli per condition and thus a sufficient signal to noise ratio to study the N400 of a given subject.

\section{Acknowledgments}

This study was supported by grant 194517-02 from the Natural Sciences and Engineering Research Council of Canada (NSERC) allocated to J.B. Debruille who is supported by the scholarship 10084 from the Fonds de la Recherche en Santé du Québec (FRSQ). Louis Renoult was supported by FRSQ fellowships 13542 and 23710.

\section{References}

Awh, E., Barton, B., Vogel, E.K., 2007. Visual working memory represents a fixed number of items regardless of complexity. Psychol. Sci. 18, 622-628. 
Bach, P., Gunter, T.C., Knoblich, G., Prinz, W., Friederici, A.D., 2009. N400-like negativities in action perception reflect the activation of two components of an action representation. Soc. Neurosci. 4, 212-232.

Barsalou, L.W., 2008. Representation and knowledge in long-term memory. In E.E. Smith \& S.M. Kosslyn (Textbook authors). Cognitive psychology: Mind and brain (pp. 147-191). Upper Saddle River, NJ: Prentice-Hall.

Besson, M., Kutas, M., Van Petten, C., 1992. An event-related potential analysis of semantic congruity and repetition effects in sentences. J. Cogn. Neurosci. 4, 132-149.

Binder, J.R., Desai, R.H., Graves, W.W., Conant, L.L., 2009. Where Is the Semantic System? A Critical Review and Meta-Analysis of 120 Functional Neuroimaging Studies. Cereb. Cortex 19, 2767-2796.

Chang, T., 1986. Semantic memory: facts and models. Psychol. Bull. 99, 199-220.

Chwilla, D.J., Kolk, H.H., 2005. Accessing world knowledge: evidence from N400 and reaction time priming. Brain Res. Cogn. Brain Res. 25, 589-606.

Collins, A.M., Loftus, E.F., 1975. A spreading activation theory of semantic processing. Psychol. Rev. 82, 407-428.

Collins, A.M., Quillian, M.R., 1969. Retrieval time from semantic memory. J. Verb. Learn. Verb. Behav. 8, 240-247.

Collins, A.M., Quillian, M.R., 1970. Does category size affect categorization time? J. Verb. Learn. Verb. Behav. 9, 432-438.

Content, A., Mousty, P., Radeau, M., 1990. Une base de données lexicales informatisée pour le français écrit et parlé. Ann. Psychol. 90, 551-566.

Cowan, N., 1988. Evolving conceptions of memory storage, selective attention, and their mutual constraints within the human information-processing system. Psychol. Bull. 104, 163-191.

Cowan, N., 1993. Activation, attention, and short-term memory. Mem. Cognit. 21, $162-167$.

Curran, T., Tucker, D.M., Kutas, M., Posner, M.I., 1993. Topography of the N400: brain electrical activity reflecting semantic expectancy. Electroencephalogr. Clin. Neurophysiol. 88, 188-209.

D'Arcy, R.C., Service, E., Connolly, J.F., Hawco, C.S., 2005. The influence of increased working memory load on semantic neural systems: a high-resolution eventrelated brain potential study. Brain Res. Cogn. Brain Res. 22, 177-191.

Deacon, D., Mehta, A., Tinsley, C., Nousak, J.M., 1995. Variation in the latencies and amplitudes of N400 and NA as a function of semantic priming. Psychophysiology 32, 560-570.

Debruille, J.B., Renoult, L., 2009. Effects of semantic matching and of semantic category on reaction time and $\mathrm{N} 400$ that resist numerous repetitions. Neuropsychologia 47 506-517.

Duncan, C.C., Barry, R.J., Connolly, J.F., Fischer, C., Michie, P.T., Näätänen, R., Polich, J. Reinvang, I., Van Petten, C., 2009. Event-related potentials in clinical research: guidelines for eliciting, recording, and quantifying mismatch negativity, P300, and N400. Clin. Neurophysiol. 120, 1883-1908.

Electrode Position Nomenclature Committee, 1991. American Electroencephalographic Society Guidelines for standard electrode position nomenclature. J. Clin. Neurophysiol. 8, 200-202.

Elger, C.E., Grunwald, T., Lehnertz, K., Kutas, M., Helmstaedter, C., Brockhaus, A., Van Roost, D., Heinze, H.J., 1997. Human temporal lobe potentials in verbal learning and memory processes. Neuropsychologia 35, 657-667.

Federmeier, K.D., Laszlo, S., 2009. In: Ross, B.H. (Ed.), Time for meaning: electrophysiology provides insights into the dynamics of representation and processing in semantic memory. : Psychology of Learning and Motivation, Volume 51. Elsevier, Holland.

Franklin, M.S., Dien, J., Neely, J.H., Huber, E., Waterson, L.D., 2007. Semantic priming modulates the N400, N300, and N400RP. Clin. Neurophysiol. 118, 1053-1068.

Friedman, D., Johnson, J.R., 2000. Event-related potential ERP studies of memory encoding and retrieval: a selective review. Microsc. Res. Tech. 51, 6-28.

Greenhouse, G.W., Geisser, S., 1959. On methods of analysis of profile data. Psychometrika 24, 1582-1589.

Guillem, F., N'Kaoua, B., Rougier, A., Claverie, B., 1995. Intracranial topography of eventrelated potentials (N400/P600) elicited during a continuous recognition memory task. Psychophysiology 32, 382-392.

Guillem, F., Rougier, A., Claverie, B., 1999. Short- and long-delay intracranial ERP repetition effects dissociate memory systems in the human brain. J. Cogn. Neurosci. 11, 437-458.

Gunter, T.C., Jackson, J.L., Mulder, G., 1995. Language, memory, and aging: an electrophysiological exploration of the N400 during reading of memory-demanding sentences. Psychophysiology 32, 215-229.

Hagoort, P., Hald, L., Bastiaansen, M., Peterson, K.M., 2004. Integration of word meaning and world knowledge in language comprehension. Science 304, 438-441.

Halgren, E., Baudena, P., Heit, G., Clarke, J.M., Marinkovic, K., Chauvel, P., Clarke, M. 1994. Spatio-temporal stages in face and word processing. 2. Depth-recorded potentials in the human frontal and Rolandic cortices. J. Physiol. Paris 88, 51-80.

Heinze, H.J., Muente, T.F., Kutas, M., 1998. Context effects in a category verification task as assessed by event-related brain potential ERP measures. Biol. Psychol. 47, 121-135.

Helenius, P., Salmelin, R., Service, E., Connolly, J.F., 1998. Distinct time courses of word and context comprehension in the left temporal cortex. Brain 121, 1133-1142.

Holcomb, P.J., 1993. Semantic priming and stimulus degradation: implications for the role of the N400 in language processing. Psychophysiology 30, 47-61.

Johnson, R., Pfefferbaum, A., Kopell, B.S., 1985. P300 and long-term memory: latency predicts recognition performance. Psychophysiology 22, 497-507.
Karniski, W., Vanderploeg, R., Lease, L., 1993. "Virtual N400" and slow wave topography to auditory sentence incongruence. Brain Lang. 44, 58-79.

Kazmerski, V.A., Friedman, D., 1997. Effect of multiple presentations of words on eventrelated potential and reaction time repetition effects in Alzheimer's patients and young and older controls. Neuropsychiatry Neuropsychol. Behav. Neurol. 10, 32-47.

Kiefer, M., 2002. The N400 is modulated by unconsciously perceived masked words: further evidence for an automatic spreading activation account of N400 priming effects. Brain Res. Cogn. Brain Res. 13, 27-39.

Komatsu, L.K., 1992. Recent views of conceptual structure. Psychol. Bull. 112, 500-526.

Kounios, J., Holcomb, P.J., 1992. Structure and process in semantic memory: evidence from event-related brain potentials and reaction times. J. Exp. Psychol. Gen. 121, 459-479.

Kutas, M., 1987. Event-related brain potentials ERPs elicited during rapid serial visual presentation of congruous and incongruous sentences. Electroencephalogr. Clin. Neurophysiol. (Suppl. 40), 406-411.

Kutas, M., Federmeier, K.D., 2000. Electrophysiology reveals semantic memory use in language comprehension. Trends Cogn. Sci. 12, 463-470.

Kutas, M., Iragui, V., 1998. The N400 in a semantic categorization task across 6 decades. Electroencephalogr. Clin. Neurophysiol. 108, 456-471.

Kutas, M., Van Petten, C., Kluender, R., 2006. Psycholinguistics Electrified II: 1994-2005, In: Traxler, M., Gernsbacher, M.A. (Eds.), Handbook of Psycholinguistics, second edition. Elsevier, New York, pp. 659-724.

Liu, Y., Perfetti, C.A., Hart, L., 2003. ERP evidence for the time course of graphic, phonological, and semantic information in Chinese meaning and pronunciation decisions. J. Exp. Psychol. Learn. Mem. Cogn. 29, 1231-1247.

Luck, S.J., Vogel, E.K., 1997. The capacity of visual working memory for features and conjunctions. Nature 390, 279-281.

Martin, A., 2001. Functional neuroimaging of semantic memory, In: Cabeza, R., Kingstone, A. (Eds.), Handbook of Functional Neurolmaging of Cognition. MIT Press, Cambridge, pp. 153-186.

Mecklinger, A., 2000. Interfacing mind and brain: a neurocognitive model of recognition memory. Psychophysiology 37, 565-582.

Murphy, G.L., 2002. The Big Book of Concepts. MIT Press, Cambridge, MA.

Paller, K.A., Kutas, M., 1992. Brain potentials during memory retrieval provide neurophysiological support for the distinction between conscious recollection and priming. J. Cogn. Neurosci. 4, 375-391.

Picton, T.W., Bentin, S., Berg, P., Donchin, E., Hillyard, S.A., Johnson Jr., R., et al., 2000. Guidelines for using human event-related potentials to study cognition: recording standards and publication criteria. Psychophysiology 37, 127-152.

Pratarelli, M.E., 1995. Modulation of semantic processing using word length and complexity: an ERP study. Int. J. Psychophysiol. 19, 233-246.

Ranganath, C., Blumenfeld, R.S., 2005. Doubts about double dissociations between short- and long-term memory. Trends Cogn. Sci. 9, 374-380.

Renoult, L., Debruille, J.B., 2011. N400-like potentials index semantic relations between highly repeated individual words. J. Cogn. Neurosci. 23, 905-922.

Renoult, L., Brodeur, M.B., Debruille, J.B., 2010. Semantic processing of highly repeated concepts presented in single-word trials: electrophysiological and behavioral correlates. Biol. Psychol. 84, 206-220.

Renoult, L., Wang, X., Mortimer, J., Debruille, J.B., 2012. Explicit semantic tasks are necessary to study semantic priming effects with high rates of repetition. Clin. Neurophysiol. 123, 741-754.

Rugg, M.D., Curran, T., 2007. Event-related potentials and recognition memory. Trends Cogn. Sci. 11, 251-257.

Salisbury, D.F., 2004. Semantic memory and verbal working memory correlates of N400 to subordinate homographs. Brain Cogn. 55, 396-399.

Segalowitz, S.J., Van Roon, P., Dywan, J., 1997. The ERP late positivity: a graduated response to stimulus repetition. NeuroReport 8, 757-760.

Simon, G., Bernard, C., Largy, P., Lalonde, R., Rebai, M., 2004. Chronometry of visual word recognition during passive and lexical decision tasks: an ERP investigation. Int. J. Neurosci. 114, 1401-1432.

Smith, M.E., Stapleton, J.M., Halgren, E., 1986. Human medial temporal lobe potentials evoked in memory and language tasks. Electroencephalogr. Clin. Neurophysiol. 63, $145-159$.

Tulving, E., 2002. Episodic memory: from mind to brain. Annu. Rev. Psychol. 53, 1-25.

van Berkum, J.J., Hagoort, P., Brown, C.M., 1999. Semantic integration in sentences and discourse: evidence from the N400. J. Cogn. Neurosci. 11, 657-671.

Van Petten, C., Coulson, S., Rubin, S., Plante, E., Parks, M., 1999. Time course of word identification and semantic integration in spoken language. J. Exp. Psychol. Learn. Mem. Cogn. 25, 394-417.

Van Strien, J.W., Hagenbeek, R.E., Stam, C.J., Rombouts, S.A., Barkhof, F., 2005. Changes in brain electrical activity during extended continuous word recognition. NeuroImage 26, 952-959.

Voss, J.L., Federmeier, K.D., 2011. FN400 potentials are functionally identical to N400 potentials and reflect semantic processing during recognition testing. Psychophysiology 48, 532-546.

Xue, G., Dong, Q., Chen, C., Lu, Z., Mumford, J.A., Poldrack, R.A., 2010. Greater neural pattern similarity across repetitions is associated with better memory. Science 330, 97-101.

Young, M.P., Rugg, M.D., 1992. Word frequency and multiple repetition as determinants of the modulation of event-related potentials in a semantic classification task. Psychophysiology 29, 664-676. 